\title{
Correction to: Machine Learning Algorithm Guiding Local Treatment Decisions to Reduce Pain for Lung Cancer Patients with Bone Metastases, a Prospective Cohort Study
}

\author{
Zhiyu Wang · Jing Sun • Yi Sun • Yifeng Gu • Yongming Xu • \\ Bizeng Zhao · Mengdi Yang · Guangyu Yao • Yiyi Zhou • \\ Yuehua Li · Dongping Du · Hui Zhao
}

Published online: April 11, 2021

(C) The Author(s) 2021

Correction to: Pain Ther https://doi.org/10.1007/ s40122-021-00251-2

In the original publication, the equal authorship contribution statement was missing. The details are provided below:

The original article can be found online at https://doi. org/10.1007/s40122-021-00251-2.

Z. Wang $\cdot$ J. Sun $\cdot$ M. Yang $\cdot$ G. Yao $\cdot$ Y. Zhou H. Zhao ( $\square)$

Department of Internal Oncology, Shanghai Sixth People's Hospital Affiliated to Shanghai Jiaotong University, Shanghai, People's Republic of China e-mail: zhao-hui@sjtu.edu.cn

\section{Y. Sun}

Department of Radiation, Shanghai Sixth People's Hospital Affiliated to Shanghai Jiaotong University, Shanghai, People's Republic of China

Y. Gu $\cdot$ Y. Li

Department of Intervention, Shanghai Sixth People's Hospital Affiliated to Shanghai Jiaotong University, Shanghai, People's Republic of China

Y. Xu $\cdot$ D. Du $(\square)$

Department of Pain, Shanghai Sixth People's Hospital Affiliated to Shanghai Jiaotong University, Shanghai, People's Republic of China

e-mail: dudongping@hotmail.com

\section{B. Zhao}

Department of Orthopaedics, Shanghai Sixth People's Hospital Affiliated to Shanghai Jiaotong University, Shanghai, People's Republic of China
Zhiyu Wang and Jing Sun have contributed equally and should be considered as co-first authors.

The original article has been corrected.

\section{OPEN ACCESS}

This article is licensed under a Creative Commons Attribution-NonCommercial 4.0 International License, which permits any noncommercial use, sharing, adaptation, distribution and reproduction in any medium or format, as long as you give appropriate credit to the original author(s) and the source, provide a link to the Creative Commons licence, and indicate if changes were made. The images or other third party material in this article are included in the article's Creative Commons licence, unless indicated otherwise in a credit line to the material. If material is not included in the article's Creative Commons licence and your intended use is not permitted by statutory regulation or exceeds the permitted use, you will need to obtain permission directly from the copyright holder. To view a copy of this licence, visit http://creativecommons.org/licenses/by$\mathrm{nc} / 4.0 /$. 